\title{
An Empirical Study on the Influence of the Mobile Information System on Sports and Fitness on the Choice of Tourist Destinations
}

\author{
Yan Weng \\ Jiujiang University, Jiujiang 332005, Jiangxi, China \\ Correspondence should be addressed to Yan Weng; 2006030407@st.btbu.edu.cn
}

Received 30 August 2021; Revised 8 October 2021; Accepted 12 October 2021; Published 19 November 2021

Academic Editor: Sang-Bing Tsai

Copyright (C) 2021 Yan Weng. This is an open access article distributed under the Creative Commons Attribution License, which permits unrestricted use, distribution, and reproduction in any medium, provided the original work is properly cited.

\begin{abstract}
Based on the popularity of mobile information and the important role of mobile information in marketing, the use of mobile information to publish travel information and travel advertisements has become a new choice for operators, which can also attract sports and fitness people. This article studies the influence of official microblog of tourist destination on tourists' choice of tourist destination. In this study, five factors, such as the usefulness of official microblog, are taken as independent variables, tourist destination selection as dependent variables, and the mediating role of use attitude is taken into account. A research model is established to explore the impact of these variables on tourist destination selection. The results show that usefulness, ease of use, interactivity, and entertainment have direct effects on tourists' willingness to choose tourist destinations; ease of use and interactivity can indirectly affect tourists' choice of tourist destinations using attitudes; perceived trust needs to have a positive effect on tourists' willingness to choose tourist destinations using attitudes.
\end{abstract}

\section{Introduction}

In contemporary countries, an important place in the economies of all countries is occupied by tourism. With the advent of the era of mass tourism in particular, tourism has become one of the most dynamically emerging "insurgent industries" that are inseparable from the daily life of the population and the social economy of the country. This is one of the most important ways to attract tourists to a destination through effective distribution and education $[1,2]$. So how to effectively carry out marketing communication; we must understand what factors will affect the choice of tourist destinations when tourists travel. Nowadays, many researchers have studied the influencing factors of tourism destination selection. Beerli and Martin divided the influencing factors of tourism image perception into two aspects: personal factors and information sources [3]. Based on the analysis of domestic and foreign literature, Wen et al. concluded that the influencing factors of tourism destination image include two categories: inducing elements and individual elements [4]. All the studies are basically carried out from two aspects: on the one hand, they mainly discuss the influence of the intrinsic factors of tourists themselves, such as $\mathrm{Xu}$ [5], discussing the behavioral patterns of tourists' destination selection from the perspectives of frequency, mode, and preference. On the other hand, it studies the external environmental factors of tourists, such as $\mathrm{Wu}[6]$ to analyze the impact of distance, destination attributes, and other objective factors on tourists' choice of destination. Among these two factors, in order to reduce the risk of tourism decision making, tourists need to collect external information to increase their understanding of tourist destinations, so external information has a greater impact on the choice of tourist destinations.

As the information technology has been developing rapidly and the new media has been developing at a fast pace, more channels are available for travelers to obtain tourismrelated information. With these channels include [7] tourism website, electronic magazine, blog, microblog, WeChat, and other new media platforms. These tourism information 
are presented to tourists through computer, mobile phone, and other terminal devices by means of network in the form of text, pictures, videos, and other forms. What is the relationship between these new media platforms as multimedia information carriers and tourists' choice of tourist destinations, and what impact they will have on tourists' choice of tourist destinations? Firstly, we will introduce how various forms of new media have presented tourism information to tourists, the study will analyze the impact of such new media on tourists' resort choices, starting from choosing one type of new media, including the official microblogs of destinations.

\section{Multiple New Media Platforms}

With the development of the Internet, the Internet has entered the web era [8]. The Internet has developed from the era of web1.0, which is dominated by browsing information, and the age of web2.0, which is interactive sharing, to the era of personalized aggregation, web3.0. There has been a gradual expansion of media platforms for disseminating information on the Internet. By the characteristics of communication, these media platforms can be divided into dynamic media, social media, and interpersonal [9], as shown in Figure 1. These new media contain a huge amount of information, covering many forms of media information, including text, image, sound, video, and so on. Information dissemination in new media is more targeted and interactive.

2.1. Mobile Media. Mobile media [10] takes mobile digital terminal as carrier, runs various platform software and related applications with the help of wireless digital technology and mobile digital processing technology, processes information, and displays it in many forms, such as text, picture, and video. Mobile media can directly push personalized instant information for users through mobile smart terminals, such as mobile phones, and tablets, and can interact with users in a timely manner. At present, the most popular mobile media application software is WeChat. It [11] is a free application launched by Tencent to provide instant messaging services for smart phones. To be exact, WeChat is a mobile chat software that supports the rapid transmission of free voice messages, videos, pictures, and text across communication operators and operating system platforms through the network, and it supports multipeople chatting. In WeChat, various forms of information, including text, pictures, and videos, can be disseminated through the form of sharing. WeChat propagation can be in the form of one to one and one to many. WeChat can achieve a one-to-many form of communication through the public platform. The biggest advantage of WeChat is that it can realize niche communication based on acquaintance network. The credibility and achievement rate of information dissemination is higher than that of other media.

The word-of-mouth information of a tourist destination is one of the important components of the destination information. It is not an objective data, but a tourist's information on how good or bad the tourist destination is based on their own feelings and experiences. Similar to word-of-mouth information is tourist destination impression information, but impression information not only comes from the dissemination of tourists but also includes impressions created by tourism operators through various methods such as advertising and marketing.

2.2. Social Media. Social media [12] refers to a series of tools based on the network or mobile devices to facilitate the sharing and discussion of information between people. It emphasizes user participation. Users are not only information creators of social media but also information sharing and disseminators. There are many kinds of social media. Social media can be divided into seven categories from the two dimensions of content and mode of communication. As shown in Figure 2, the order of vertical content dissemination from single to rich is collaborative tools: blog, social networking site, content aggregation community, microblog, virtual community, and cross-media applications. Among them, collaborative tools have the simplest communication content, which is only in the form of text. Then, it goes from text to pictures to videos and finally to all three. Horizontal content dissemination is from concentration to dissemination, such as social media, generally from a single fixed website visit mode to the visit dissemination of various social nodes. The concepts, manifestations, and characteristics of various social media are shown in Table 1.

2.3. Search Engine. There are many search engines in new media environment, such as search engine [13], which can respond to the user's search request and search for relevant information. Search engines can quickly respond to search requests submitted by users when they enter with keywords and search for the required relevant information. According to statistics, about 160 million consumers in China use search engines to query relevant product information before shopping. The huge user base also creates excellent opportunities for businesses to promote products and services. In order to understand the price, performance, and word of mouth of products, consumers usually use search engines to search for relevant information of products before consumption. At this time, consumers change from passive "push" mode to active "search" mode. Search engine marketing is based on search engine platform, using people's dependence on search engines and users' habits, when people search for keyword information, as far as possible will be related to marketing information to target customers. For the moment, resort search engine mining is the search and optimization of destination shopping websites to explore more potential visitors and realize higher conversion rates. Nowadays, search engine has become the most important communication bridge between both consumers and enterprises, and it is one of the best planks for "precision advertising.

2.4. Mass Media New Media. The mass media [14] is a specialized media organization that conducts large-scale information dissemination activities to the audience through 


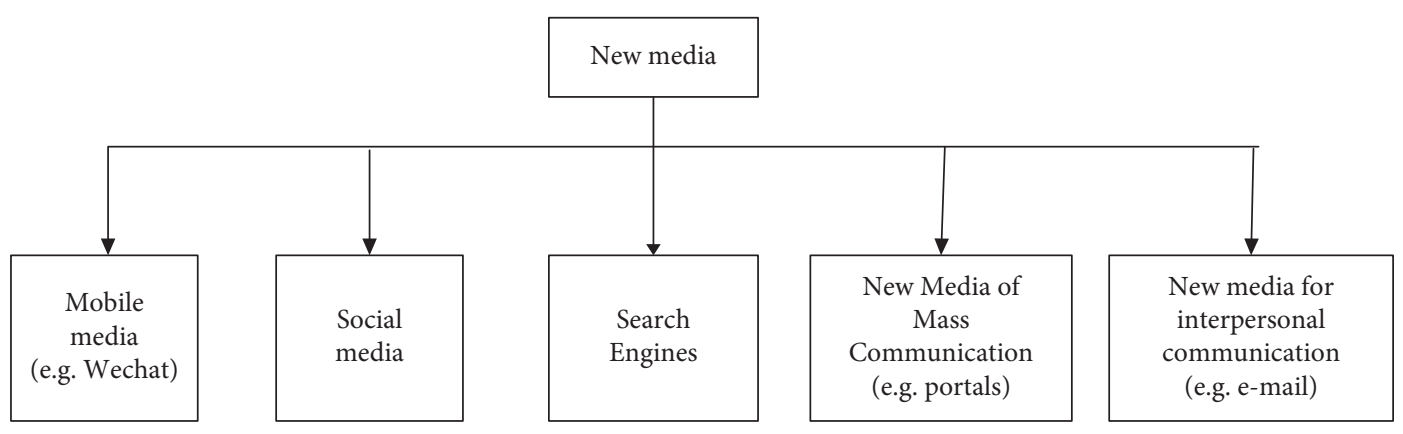

Figure 1: New media classification.

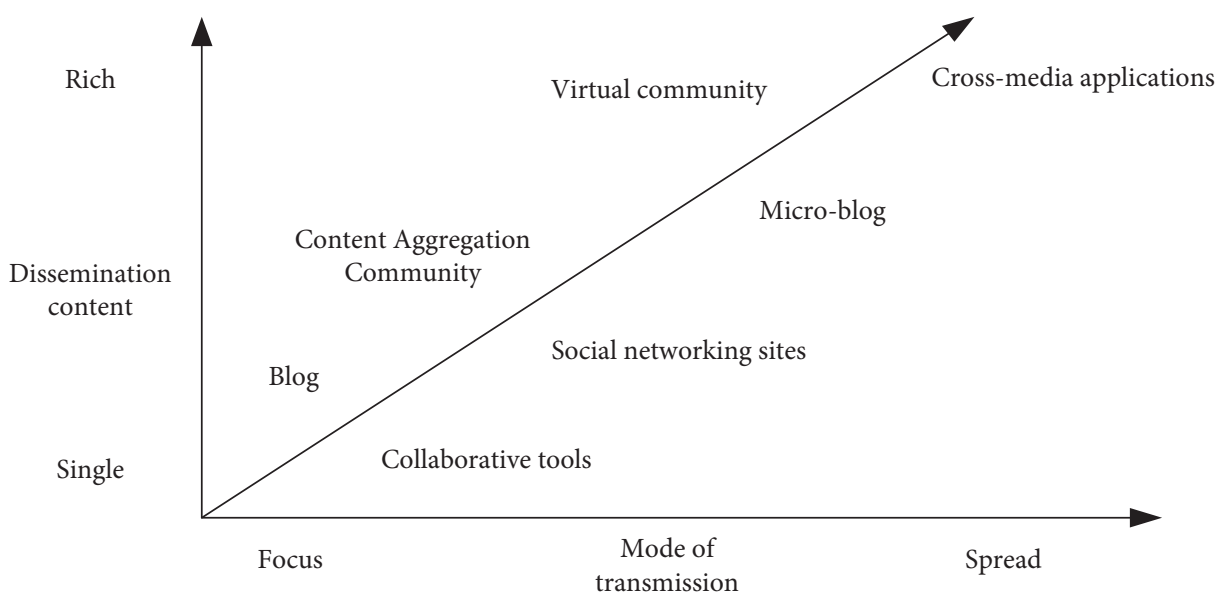

FIGURE 2: Social media classification.

a certain media. It is organizational; it is open in content; it has strong selectivity in audience, communication tools, content, and participation time. The speed of communication is faster, and the information circulation is interactive. Portal websites, electronic magazines, and so on belong to the mass media. Among them, the portal website can convey deeper and broader marketing information to consumers and has the function of realizing consumers' interactive participation. The interactive participation of audiences makes information dissemination more effective. In the new media environment, the audience is not only the recipient of information but also the creator and disseminator of information.

\subsection{New Media of Interpersonal Communication.} Communication between the people refers to the exchange of information between individuals. There, it can be either direct face-to-face communication or intermediary mediamediated indirect communication. Transpersonal communication [15] is one of the most common forms of communication in the new media. Other forms of communication interact for each other. The main forms of interpersonal communication through new media are email, instant messaging, and so on. E-mail has played an important role in the promotion of business information. E-mail marketing has become an important means of low- cost marketing for many enterprises. Then, it developed into licensed e-mail marketing. Licensed e-mail is usually based on information that users are interested in, often accompanied by advertising content. It is received by the recipient who joins the mailing list on his own initiative.

Although there are many kinds of new media, from the content point of view, each new media has the characteristics of large amount of information, diverse forms, and fast retrieval. Also, it weakens the boundaries between communicators and audiences. What it does is weaken the barriers between propagators and audiences. Its characteristics are fast, targeted, interactive, and low cost of communication. So the influence of new mediators on tourists' choice of tourist to travel destinations should be comparable. Therefore, this article studies the impact of microblog on tourists' choice of tourist destination and takes its analysis results as the impact of new media on tourists' choice of tourist destination.

\section{Influence of Tourist Destination Official Microblog on the Choice of Tourists in Tourist Destinations}

3.1. Official Microblog of Tourist Destination. With the development of the Internet, new forces are emerging in social media. From blog to SNS to microblog, microblog is the most widely used and lasting effect [16]. With the popularity of 
TABle 1: Concepts, representations, and characteristics of various social media.

\begin{tabular}{|c|c|c|c|}
\hline $\begin{array}{l}\text { Social media } \\
\text { category }\end{array}$ & Definition & Representative & Characteristics \\
\hline $\begin{array}{l}\text { Collaborative } \\
\text { tools }\end{array}$ & $\begin{array}{l}\text { Allowing anyone to participate is an } \\
\text { encyclopedia collaboration with content } \\
\text { contributed by the whole people. }\end{array}$ & $\begin{array}{l}\text { Wikipedia, Baidu } \\
\text { Encyclopedia }\end{array}$ & $\begin{array}{l}\text { The content is text, and the mode of } \\
\text { dissemination focuses on visiting fixed } \\
\text { websites. }\end{array}$ \\
\hline Blog & $\begin{array}{l}\text { It is a simple way to publish personal } \\
\text { information. Blog combines text, images, } \\
\text { website links, and other people's blogs or } \\
\text { related topics, making full use of the } \\
\text { characteristics of network interaction and } \\
\text { real-time updates, so that users can } \\
\text { quickly access information and resources, } \\
\text { while visitors can also leave interactive } \\
\text { opinions. }\end{array}$ & $\begin{array}{l}\text { Sina, NetEase, Sohu, and other } \\
\text { blogs }\end{array}$ & $\begin{array}{l}\text { It has the dual characteristics of network } \\
\text { group communication and network mass } \\
\text { communication. }\end{array}$ \\
\hline $\begin{array}{l}\text { Social networking } \\
\text { sites }\end{array}$ & $\begin{array}{l}\text { It is a service based on Internet. Users } \\
\text { build an open or semipublic image in a } \\
\text { specific network system, listing their } \\
\text { various contacts for communication and } \\
\text { interaction. }\end{array}$ & $\begin{array}{l}\text { Facebook, Myspace, Microsoft } \\
\text { Windows Livespaces, Tencent } \\
\text { Qzone, Renren, and Douban }\end{array}$ & $\begin{array}{l}\text { Users of social networking sites are usually } \\
\text { "acquaintances." User data are relatively } \\
\text { real. Users can be easily screened } \\
\text { according to geographical location and } \\
\text { income status, and target groups can be } \\
\text { effectively identified, so as to carry out } \\
\text { targeted publicity and marketing } \\
\text { interaction. }\end{array}$ \\
\hline $\begin{array}{l}\text { Content } \\
\text { aggregation } \\
\text { community }\end{array}$ & $\begin{array}{l}\text { Users classify and share websites with } \\
\text { text, pictures, videos, etc. }\end{array}$ & Video website & $\begin{array}{l}\text { Good intuition, strong appeal, diverse } \\
\text { forms, strong interaction, active } \\
\text { transmission, low cost, etc. }\end{array}$ \\
\hline Microblog & $\begin{array}{l}\text { The abbreviation of microblog is a } \\
\text { platform for disseminating, sharing, and } \\
\text { acquiring information based on user } \\
\text { relationship }\end{array}$ & $\begin{array}{l}\text { Twitter, Sina, Tencent, Sohu } \\
\text { and NetEase }\end{array}$ & $\begin{array}{l}\text { Simplified form, convenient operation, } \\
\text { powerful function, convenient use of } \\
\text { mobile client, large generation group, fast } \\
\text { transmission speed, strong timeliness, } \\
\text { high freshness. }\end{array}$ \\
\hline $\begin{array}{l}\text { Virtual } \\
\text { community }\end{array}$ & $\begin{array}{l}\text { It is a convenient place for new media } \\
\text { users with similar hobbies, experiences, } \\
\text { business-related or professional interests } \\
\text { to gather, communicate, and share. }\end{array}$ & BBS and online games & User participation is high. \\
\hline
\end{tabular}

microblog, it has become an important platform for tourists to express their opinions and obtain information easily. Before traveling, through microblog, tourists can easily get information about food, shelter, travel, and other tourist experiences shared by others and designate travel plans and routes. In tourism, tourists can share their travel experience at any time through microblog. After tourism, tourists spread the feeling of after-tour in the form of words and pictures, affecting more other tourists to travel to the tourist destination. The acquisition and publication of information on microblog leads to a virtuous circle of tourism behavior. Therefore, more and more tourism governments attach importance to the construction of microblog. According to data [17], many tourism departments in China's provinces and cities have launched real-name authentication microblogs in Sina and Tencent. Therefore, the official microblog of tourism destination in China has been quite popular.

The main purpose of official microblog of tourist destination is to display the image of tourist destination, improve the popularity of tourist destination, and ultimately achieve enormous economic and social benefits. With the official representative of its tourist destination being the destination management body, it has greater authority and publicity than the ordinary personal microblog. It would thus have some influence on the consumer's choice of their travel destination.

3.2. Research Model. In order to study the influence of official microblog on tourists' destination choice, this study constructed a research model of official microblog tourists' destination choice. In the model [18], there are five factors that influence the attitude of using a tourism destination's official microblog: usefulness, user-friendliness, interactivity, entertainment, and with perceived trust. We then developed a model including these five factors as independent variables, tourism destination choice as dependent variable, and considering the mediate role of usage intention, a model is established as shown in Figure 3. Through this model, the influence mechanism of these five variables on tourist destination selection-dependent variable is explored.

The meaning of each variable is defined by the following documents as follows [19-21]:

(i) Easy of use: how easy it is for tourists to expect to use official microblogs in tourist destinations 


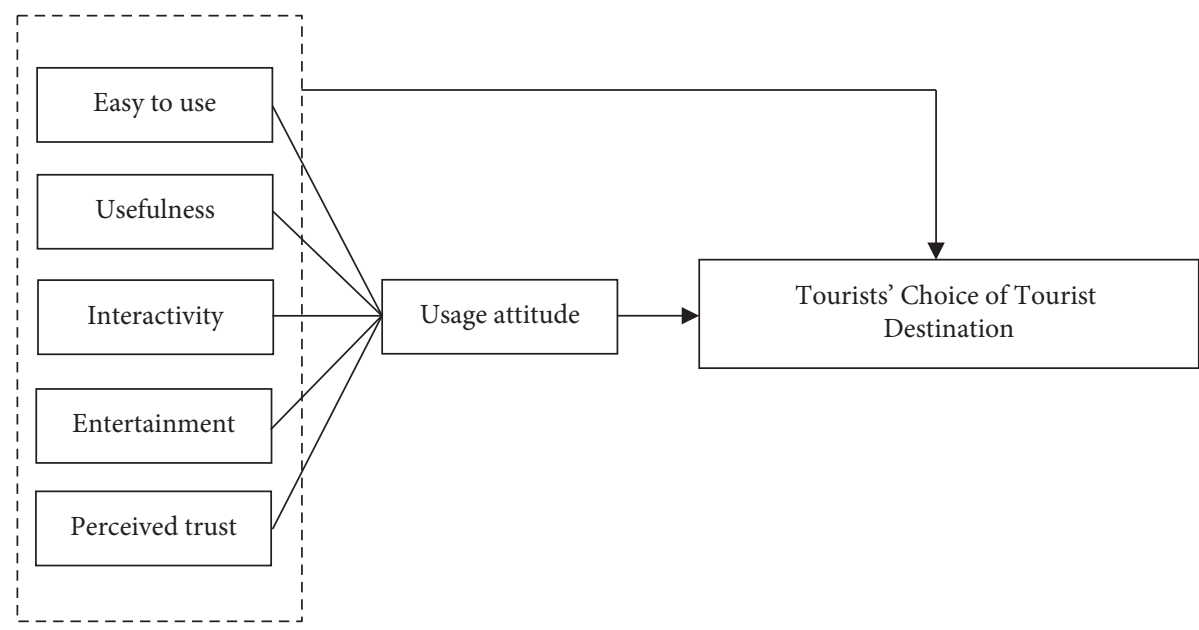

Figure 3: Research model.

(ii) Usefulness: tourists using official microblogs of tourist destinations can help to obtain tourism information and improve travel efficiency

(iii) Entertainment: travelers think that microblogs in tourist destinations can get information, kill time, relieve pressure, and be happy to use them

(iv) Interactivity: two-way information interaction between tourists and their microblog participants or participants

(v) Perceived trust: tourists believe that the information of tourism destination microblog is true, effective, and credible and that microblog is based on the needs of users, not for profit

3.3. Data Sampling. In this study, a questionnaire survey was used to obtain data samples. The form of questionnaire is mainly network questionnaire, supplemented by paper questionnaire. Questionnaire sampling was conducted by random sampling. With the online questionnaire the main purpose as to send the link address of the questionnaire by e-mail to listeners and neighbors and friends of the official microblog of the tourist destination. A number of questionnaires were sent out 1000 and 842 were returned. 100 paper questionnaires were distributed on site and 86 questionnaires to be returned $[22,23]$. Then, the questionnaire was processed, and 776 valid questionnaires were screened out, as shown in Table 2.

3.4. Analysis Process. The correlation analysis is a statistical method to study the uncertainties among variables [24, 25]. Generally, the correlation coefficient Pearson is used to express the degree of correlation. In this study, Pearson correlation coefficient is used to analyze the degree of correlation between variables. The closer the absolute value of correlation coefficient is to 1 , the higher the degree of correlation between variables. This part examines whether there is a significant correlation between usage attitude and its five influencing factors (usefulness, ease of use, interactivity, entertainment, perceived trust). The results are shown in Table 3 . Table 3 shows that usefulness, ease of use, interactivity, and entertainment are positively correlated with willingness to use at 0.01 level. It is preliminarily proved that the higher the usefulness, ease of use, interactivity, and entertainment of official microblog, the stronger the attitude of tourists willing to use microblog.

This part examines whether there is a significant correlation between tourists' choice of destination and its influencing factors (usefulness, ease of use, interactivity, entertainment, perceived trust). The results are shown in Table 4 .

Table 4 shows that usefulness, ease of use, interactivity, entertainment, and perceived trust are positively correlated with willingness to use at 0.01 level. It is preliminarily proved that the higher the usefulness, ease of use, interactivity, entertainment, and perceived trust of official microblog, the stronger the tourists' willingness to choose tourist destinations.

This study uses software AMOS 17.0 to conduct structural equation model analysis, and further explores the relationship between usefulness, ease of use, interactivity, entertainment, perceived trust, use attitude, and tourists' willingness to choose tourist destinations based on the previous correlation analysis. Among them [26-28], SEM (Structural Equation Modeling) belongs to multivariate statistics, which integrates path analysis and factor analysis statistical methods. The indirect, direct, or total effects of independent variables on dependent variables are obtained through the relationship between potential variables and dominant variables included in the model. The results of the relationship among five factors, such as usefulness, attitude to use, and tourists' willingness to choose tourist destinations are shown in Table 5 . From the standardized path coefficients and significance levels of the model variables in Table 5 , it can be seen that the fitting level of the initial model, and the secondary modified model has been greatly improved.

The direct, indirect, and total effects of the variables modified by the structural equation model are shown in Table 6. Among them, attitudes play a mediating role in antecedent variables and outcome variables (tourists' willingness to act). 
TABLE 2: Number of questionnaires issued and number of recycling done.

\begin{tabular}{lccccc}
\hline Distribution form & Number of issues & Recycling quantity & Recovery rate (\%) & Effective quantity & Efficient (\%) \\
\hline E-mail & 1000 & 842 & 84.2 & 712 & 84.56 \\
Paper questionnaire & 100 & 86 & 86 & 64 & 74.4 \\
Total & 1100 & 928 & 84.36 & 776 & 83.62 \\
\hline
\end{tabular}

TABLE 3: The correlation between willingness to use and its influencing factors.

\begin{tabular}{lcc}
\hline Factor & & Use attitude \\
\hline \multirow{2}{*}{ Usefulness } & Pearson correlation coefficient & $0.612^{* *}$ \\
& Two-tailed significance test & 0.000 \\
\hline \multirow{2}{*}{ Ease of use } & Pearson correlation coefficient & $0.523^{* *}$ \\
& Two-tailed significance test & 0.000 \\
\hline \multirow{2}{*}{ Interactivity } & Pearson correlation coefficient & $0.521^{* *}$ \\
& Two-tailed significance test & 0.000 \\
\multirow{2}{*}{ Entertaining } & Pearson correlation coefficient & $0.244^{* *}$ \\
Perceived trust & Two-tailed significance test & 0.000 \\
& Pearson correlation coefficient & $0.582^{*}$ \\
& Two-tailed significance test & 0.000 \\
\hline
\end{tabular}

${ }^{* *}$ Significant correlation at 0.01 significant level (two-tailed). ${ }^{*}$ Significant correlation at 0.05 significant level (two-tailed).

TABLE 4: The relationship between tourists' choice of destination and its influencing factors.

\begin{tabular}{lcc}
\hline Factor & & Use attitude \\
\hline \multirow{2}{*}{ Usefulness } & Pearson correlation coefficient & $0.552^{* *}$ \\
& Two-tailed significance test & 0.000 \\
\hline \multirow{2}{*}{ Ease of use } & Pearson correlation coefficient & $0.263^{* *}$ \\
& Two-tailed significance test & 0.000 \\
\hline \multirow{2}{*}{ Interactivity } & Pearson correlation coefficient & $0.458^{* *}$ \\
& Two-tailed significance test & 0.000 \\
Entertaining & Pearson correlation coefficient & $0.356^{* *}$ \\
Perceived trust & Two-tailed significance test & 0.000 \\
\hline
\end{tabular}

${ }^{*}$ Significant correlation at 0.01 significant level (two-tailed). * Significant correlation at 0.05 significant level (two-tailed).

TABLE 5: Quadratic correction study coefficient and significance level between model variables.

\begin{tabular}{lcccc}
\hline & & & Estimate & CR \\
\hline Usage attitude & $<---$ & Usefulness & 0.3125 & 2.8652 \\
Usage attitude & $<---$ & Ease of use & 0.1845 & 0.0032 \\
Usage attitude & $<---$ & Interactivity & 0.4156 & 4.0125 \\
Usage attitude & $<---$ & Entertaining & 0.2013 & 0.263 \\
Tourists choose behaviors for tourist destinations & $<---$ & Usefulness & 0.3214 & 2.0135 \\
Tourists choose behaviors for tourist destinations & $<---$ & Ease of use & -0.2185 & 0.0325 \\
Tourists choose behaviors for tourist destinations & $<---$ & Interactivity & 0.0125 & -3.1694 \\
Tourists choose behaviors for tourist destinations & $<---$ & Entertaining & 0.2014 & 0.0014 \\
Tourists choose behaviors for tourist destinations & $<---$ & Perceived trust & 0.2712 & 3.4103 \\
\hline
\end{tabular}

TABLE 6: Indirect effects among variables.

\begin{tabular}{|c|c|c|c|c|c|}
\hline & $\begin{array}{c}\text { Ease of } \\
\text { use }\end{array}$ & Usefulness & Interactivity Entertaining & $\begin{array}{c}\text { Perceived } \\
\text { trust }\end{array}$ & $\begin{array}{c}\text { Usage } \\
\text { attitude }\end{array}$ \\
\hline $\begin{array}{l}\text { Usage attitude tourists choose their willingness to travel } \\
\text { destinations }\end{array}$ & 0.0775 & & 0.0465 & 0.1523 & \\
\hline
\end{tabular}

As shown in Table 6, the usefulness, ease of use, interactivity, and entertainment of official microblogs have direct effects on tourists' willingness to choose tourism destinations among the factors that influence tourists' willingness to choose tourism destinations. With that said, these four factors can have both direct and positive effects on 
tourists' will to select tourist destinations through official tourism destination microblogs, for example, while ease of use and interactivity can influentially affect tourists' choice of tourist destinations by attitude directly. Perceived trust needs to have a positive effect on tourists' willingness to choose their destination using attitudes. It can be seen that attitudes play a very significant role in mediating the willingness of tourists to use official microblogs of tourist destinations in the choice of tourist destinations.

\section{Result Analysis}

(1) Usefulness has a positive impact on the user's willingness to choose destination. When users think that the official microblog information of a tourist destination is very useful for them to choose a tourist destination and get more effective information from it, users will have a stronger willingness to choose the behavior of the tourist destination. On the contrary, when users think that using official microblog is not very helpful to them, then users' willingness to choose the destination will be weaker.

(2) When users think that the official microblog of tourism destination is easy to use and can bring convenience to themselves, they will have a positive attitude towards the official microblog of tourism destination, and in the near future, enhance the official microblog of tourism destination to affect their willingness to choose tourism destination. On the contrary, if the operation of official microblog in tourism destination is rather complicated and users find it very difficult to use it, users will have resistance to microblog, resulting in unwillingness to choose tourism destination.

(3) When the official microblog of a tourist destination has a strong interaction with users, users will have a positive attitude to use it, thereby increasing their willingness to choose the behavior of the tourist destination. On the contrary, when users use official microblogs of tourist destinations, the interaction between microblogs and users is weak, or even if there is no such interaction, users will have negative attitudes, thereby reducing the willingness to choose the tourist destinations.

(4) Users feel very happy when they use official microblogs of tourist destinations. Users' willingness to choose a tourist destination is stronger; conversely, when the official microblog users of the tourist destination use microblog, they feel unhappy, which will reduce the willingness of tourists to choose the tourist destination.

(5) If users have a strong sense of trust in official microblogs of tourist destinations, users will actively use official microblogs to obtain information. But this kind of trust will not enhance the user's willingness to choose the destination.

\section{Conclusion}

With the rapid development of information technology and the rapid development of new media, the media platform for disseminating information on the network is gradually enriched. These media platforms can be divided into mobile media, social media, search engines, mass media, and interpersonal media according to their communication characteristics. Tourists can easily and quickly get more relevant information about tourism from these new media. What impact will these new media have on tourists' choice of destination? Although there are many kinds of new media, the impact of new media on tourists' choice of tourist destination should be similar. Therefore, this article studies the impact of official microblog on tourists' choice of tourist destinations and takes its analysis results as the impact of new media on tourists' choice of tourist destinations. The following work has been done in this study:

(1) Introduce the concepts, characteristics, and ways of information transmission of new media

(2) This study takes the usefulness and ease of use of official microblogs of tourist destinations as independent variables, takes the choice of tourist destinations as dependent variables, and considers the mediating role of attitudes to use, establishing a research model to explore the impact mechanism of these variables on the choice of tourist destinations

The results show that among the factors affecting tourists' willingness to choose destination, usefulness, ease of use, interactivity, and entertainment have direct effects on tourists' willingness to choose destination. Easy-to-use and interactivity can indirectly affect tourists' choice behavior of tourist destinations using attitudes. Perceived trust needs to have a positive effect on tourists' willingness to choose tourist destinations using attitudes.

\section{Data Availability}

This article does not cover data research. No data were used to support this study.

\section{Conflicts of Interest}

The author declares no conflicts of interest.

\section{Acknowledgments}

This work was supported by the 2021 project of the 14th Five-Year Plan of Education Science of Jiangxi Province, Research on the Innovative Training of Mass Fitness Sports Talents in Universities from the Perspective of "Integration of Sports and Tourism," under project number 21YB203.

\section{References}

[1] W. Xinyue and H. Juanjuan, "Spatial distribution features and influence factors of rural leisure tourism destinations in shandong province," Scientia Geographica Sinica, vol. 36, no. 11, pp. 1706-1714, 2016. 
[2] A. D. Ardhala, E. B. Santoso, and H. Sulistyarso, "Influence factors on the development of creative industry as tourism destination (case study: footwear village in Mojokerto city)," Procedia-Social and Behavioral Sciences, vol. 227, pp. 671679, 2016.

[3] A. Beerli and J. D. Martín, "Factors influencing destination image," Annals of Tourism Research, vol. 31, no. 3, pp. 657-681, 2004.

[4] C. Wen, L. Li, W. Xu, and Q. Zhang, "Summary of tourism destination image research," Geography and Geographic Information Science, vol. 25, no. 6, pp. 105-109, 2009.

[5] J. Xu, "An analysis of tourism behavior characteristics of Beijing residents," Tourism Tribune, vol. 21, no. 8, pp. 34-39, 2006.

[6] B. Wu, "A study on the destination choice behavior of urban residents in China," Journal of Geography, vol. 52, no. 2, pp. 97-103, 1997.

[7] P. N. Howard, "Network ethnography and the hypermedia organization: new media, new organizations, new methods," New Media \& Society, vol. 4, no. 4, pp. 550-574, 2002.

[8] A. Aykas, A. Uslu, and C. Şimşek, "Mass media, online social network, and organ donation: old mistakes and new perspectives," Transplantation Proceedings, vol. 47, no. 4, pp. 1070-1072, 2015.

[9] J. Choi and J. K. Lee, "Investigating the effects of news sharing and political interest on social media network heterogeneity," Computers in Human Behavior, vol. 44, no. 44, pp. 258-266, 2015.

[10] J. Gardner and K. Lehnert, "What's new about new media? how multi-channel networks work with content creators," Business Horizons, vol. 59, no. 3, pp. 293-302, 2016.

[11] S. A. Rains and S. R. Brunner, "What can we learn about social network sites by studying facebook? a call and recommendations for research on social network sites," New Media \& Society, vol. 17, no. 1, pp. 114-131, 2015.

[12] M. Migliorati, "La comunicazione odontoiatrica nell'era dei new media," Dental Cadmos, vol. 84, no. 1, pp. 16-29, 2016.

[13] T. Liu, D. Liang, L. Song, V. M. Nace, and B. Chu, "Spatial open-network formed by mixed triblock copolymers as a new medium for double-stranded DNA separation by capillary electrophoresis," Electrophoresis, vol. 22, no. 3, pp. 449-458, 2001.

[14] C.-K. Pai, M. L. Xia, and T.-W. Wang, "A comparison of the official tourism website of five east tourism destinations," Information Technology \& Tourism, vol. 14, no. 2, pp. 97-117, 2014.

[15] F. V. S. Melo and D. S. D. Silveira, "The blind can "seeing" tourist destinations in the internet? an analysis of the accessibility of official websites of Brazilian states," Revista Brasileira De Pesquisa Em Turismo, vol. 14, no. 1, pp. 281-295, 2013.

[16] Y.-C. Chen, R.-A. Shang, and M.-J. Li, “The effects of perceived relevance of travel blogs' content on the behavioral intention to visit a tourist destination," Computers in Human Behavior, vol. 30, pp. 787-799, 2014.

[17] P. D. Student and R. Tudor, "The image of tourist destinations represented in travel blog photography. case study: Romania's image reflectedc in French bloggers photos," Revista De Turism Studii Si Cercetari in Turism, vol. 13, no. 13, pp. 32-39, 2012.

[18] Y. Rosseel, "Lavaan: an $\mathrm{R}$ package for structural equation modeling," Journal of Statistical Software, vol. 48, no. 2, pp. 1-36, 2011.
[19] Y. Xing and Y. Chang, "Review of weibo research," Intelligencer Journal, vol. 30, no. 9, pp. 61-65, 2011.

[20] Y. Yang, L. Bai, and Z. Su, "Structural and unstructured comparative study of tourism destination image: a case study of Yangshuo tourism image measurement and analysis," Journal of Tourism, vol. 22, no. 4, pp. 53-57, 2007.

[21] J. F. Hair, M. Sarstedt, C. M. Ringle, and J. A. Mena, "An assessment of the use of partial least squares structural equation modeling in marketing research," Journal of the Academy of Marketing Science, vol. 40, no. 3, pp. 414-433, 2012.

[22] G. Xiao, Q. Cheng, and C. Zhang, "Detecting travel modes using rule-based classification system and Gaussian process classifier," IEEE Access, vol. 7, pp. 116741-116752, 2019.

[23] G. Xiao and Z. Wang, "Empirical study on bikesharing brand selection in China in the post-sharing era," Sustainability, vol. 12 , no. 8 , p. $3125,2020$.

[24] J. Henseler, C. M. Ringle, and M. Sarstedt, "A new criterion for assessing discriminant validity in variance-based structural equation modeling," Journal of the Academy of Marketing Science, vol. 43, no. 1, pp. 115-135, 2015.

[25] B. Muthén and T. Asparouhov, "Bayesian structural equation modeling: a more flexible representation of substantive theory," Psychological Methods, vol. 17, no. 3, pp. 313-335, 2012.

[26] J. F. Hair, C. M. Ringle, and M. Sarstedt, "Corrigendum to "editorial partial least squares structural equation modeling: rigorous applications, better results and higher acceptance" [LRP 46/1-2 (2013) 1-12]," Long Range Planning, vol. 47, no. 6 , p. $392,2014$.

[27] R. H. Hoyle, "Handbook of structural equation modeling," Structural Equation Modeling, vol. 20, no. 2, pp. 354-360, 2012.

[28] W. Xue, SPSS Statistical Analysis Method and Its Application, Electronic Industry Publishing House, Beijing, China, 2006. 